\title{
Policy Interventions to Contemporary Challenges and the Performance of Insurance Companies in Kenya a Case Study of Jubilee Insurance Company
}

\author{
Benjamin O. Abongo \\ PhD Candidate: Kenya Methodist University, Kenya \\ Dr. Thomas Senaji \\ PhD Kenya Methodist University, Kenya \\ Dr. Nancy Rintari \\ Kenya Methodist University, Kenya
}

\begin{abstract}
The article sought to review the contemporary challenges and their policy interventions in the Kenyan insurance industry in terms of the external and internal challenges affecting the insurance business and which require leadership and managerial actions. The researcher reviewed the contemporary challenges and the performance of insurance companies in Kenya by looking at the external business environmental challenges and how they affect the management of Insurance companies. Secondly, the study considered how Kenyan insurance companies adapt and adjust their internal practices and processes to satisfy the changing customer expectations. The article goes further to review the critical policy issues which are required to address: changing consumer dynamics, enforce strict compliance with the stringent regulations, constant product innovations, and greater need for communication, technological disruptions, on-demand marketplace, and compensation. Using peer-reviewed literature and the published integrated annual reports of Jubilee Insurance Company Ltd; the study discussed and highlighted the policy interventions in relation to the demands of business and customers. Using Jubilee Insurance as a model insurance company in a case study, the researcher found that by combining performance driven behaviour and regular use of management control systems, Insurance Companies were able to post improved results. The Choice of Jubilee was driven by its size and stability among the Kenyan insurance companies. Jubilee has adopted an integrated reporting system which enabled the researcher to obtain the empirical information required from a secondary source. The researcher reviewed the data from the company's integrated annual reports for the ten years from 2007 to 2017. The study looked at the control systems, including informal and formal controls and subjected these controls to a more comprehensive analysis to establish the impact of management control systems and strategy on the insurance company performance. The study suggested further empirical research to find the linkage between the policy interventions to various challenges and the performance of the insurance companies in Kenya.
\end{abstract}

Keywords: Insurance Sector; Contemporary challenges policy interventions; Performance.

(4) (1) CC BY: Creative Commons Attribution License 4.0

\section{Introduction}

In today's global business environment, organizations are constantly looking for ways to expand and improve their business outcomes through improved processes and adaptation of new business models. The insurance market has become highly complex as a result of rising globalization, escalating and emerging risks, and regulatory pressures. Majority of the insurance market players are advancing their business processes to cope with increasing business demands and to stay competitive in a business environment which is fast changing and which is unpredictable. Insurance involves the amalgamation of risks among policyholders and offering protection for the unfortunate few from those risks that are unforeseen. In the opinion of Hoyt and Liebenberg (2011), insurance operates on a principle of sharing the losses of a few among the many policyholders hence offering protection and peace of mind against the risk of loss to the policyholders. The effectiveness of insurance rests upon the willingness of individuals with exposure to similar risks, sharing them with others. Changing business environment is creating the need for sustainability for future viability. Kasturi (2006), observed that though the outcome of insured risks cannot be fully known, their identification, measurement and management is vital to the success of the insurer. Current developments have made it possible to access data and technology that enable greater exploitation of policyholder differences, which may price out individuals from the insurance cover, hence society end up intervening to safeguard accessibility to insurance among the vulnerable. The insurers must adapt within this challenging socio-economic environment for the business model of insurance that necessitates investment returns so as to pay claims and generate a profit for shareholders.

The business model of the insurance industry premised not only on making money from premiums received from customers but also on making money by pooling the customers' premiums to buy investments (Association of British Insurers, 2005). Investments are meant to generate a return which augments the premiums and increase the company's funds for claims settlement and re-investment in the business (Farazmand, 2003). Should the economy 
experience a prolonged low-interest rate, the insurance industry may be badly affected with insurance companies losing money from poor investment returns. The concern of an insurance company is whether the premiums and investment incomes are adequate to pay claims and meet recurrent business obligations. Insurers have created sophisticated techniques of approximating the value claims to ensure that premiums collected are adequate to at least pay all incurred claims. However, the major challenge is that no single insurance company in the world can accumulate a portfolio of risks which satisfies the law of large numbers. By partnering with reinsurance companies, the primary insurers are cushioned from some of the risks which are beyond their capacity (Swiss, 2004). Reinsurance companies are able to pool adequate portfolio of risks from different geographical locations to create capacity for insurance protection by the primary insurers.

Insurers rely on the principle of 'the law of large numbers' while striving for the reduction in risk exposure. The principle states that for a significantly large quantity of independent risks, there is a high probability that the loss expectation is very close to average. However, for the insurance of enormous risks, it might be impossible for a single insurer to underwrite sufficient independent risks that would permit reliance on the principle of the law of large numbers to minimize the overall risk. The risk to every insurer is minimized through risk sharing by a large number of independent insurers who undertake joint underwriting of the large risks designed as cooperation amongst insurers allowing sufficient diversification of risks to avail insurance cover that could otherwise not be offered by only one firm (Sain and Selimović, 2015). This cooperation has made it possible for insurers to accept some products in markets where the law of large numbers not be achieved and encourage innovation in segments of insurance clients who could otherwise not be served. From this discourse, it is clear that the contemporary insurers operate in a highly complex environment whose effects on the companies is exacerbated by the nature of the insurance business, more so in Kenya and other developing countries where insurance penetration is very low while the rate of uptake isn't improving.

Though the Kenyan insurance industry is one of the fast growing sectors, it faces serious challenges from the fast-changing technological, political, social, legal and economic environments which require constant adjustments to maintain or improve sustainable performance. The industry experiences increasing turbulence caused by intense competition, globalization, political volatility and Technological advancement. This business environment has forced changes in the way insurance business is conducted, not only in Kenya but also elsewhere in the world. These changes in the external environment are rapid, unpredictable, uncertain and discontinuous, leading to complications in the way management decisions are made within organizations meant to sustain insurance firms' relevance and securing distinctive competencies. These call for strategic leadership build upon change management, innovation, and adoption of information technology to tap on the opportunities in the environment and more effectively deal with the challenges therein.

The existence of challenges in the insurance industry is believed as the reason for the emergence of reform processes and procedures to improve internal efficiency and performance. Despite these new developments, a research gap exists where very little attention has been paid by scholars to assess the extent of influence these changes have on performance within the sector. The purpose of this study is to explore the policy interventions put in place to respond to extant contemporary challenges in the Kenyan Insurance Industry and its impact on organization performance. The study sought to offer an understanding of the contemporary challenges and their policy implications in the insurance industry and their linkage with insurance performance management in Kenya. The main objective of the study is to determine the influence of policy interventions on contemporary challenges on the performance of insurance companies in Kenya by undertaking a case study of Jubilee Insurance Company Limited. The study sought answers to the research question: how does policy interventions to contemporary challenges influence performance of Jubilee Insurance Company?

The study looked at three critical areas of policy development, practical applications, and theoretical significance. The findings of the study provide useful information for insurance companies, reinsurance companies, insurance intermediaries, and the Insurance Regulatory Authority in designing policies that improve corporate decisions among insurance companies in Kenya. Whenever the business changes, insurance companies require management control systems which can effectively address the emerging customer needs in terms of products and technological requirements for efficient customer service delivery.

The study demonstrates how organizations adapt to emerging changes and make managerial propositions on contemporary challenges, policy interventions and performance management of insurance companies in Kenya. The study contributes to the management of insurance companies by providing recommendations for effective management practices which are focused on change and which has the capability of preserving the insurance assets as a going concern. The findings in the study contribute to the development of knowledge in the way insurance companies should be managed to overcome the emerging challenges, policy issues and to increase the competencies which allow the insurance companies to thrive in a turbulent and fast-changing business environment. The study provided the researcher with a methodologically sound way to use exploratory research method to unearth a topic which is highly complex and where much study has not been previously done in Kenya.

\section{Literature Review}

\subsection{Theoretical Review}

\subsubsection{Chaos Theory}

This study is underpinned by the two related theories; Chaos and Complexity Theories. Chaos Theory is traced to the work of Henri Poincaré (1854-1912) and focuses on challenges which come with the management of change 
in organizations. According to Peters (1987), Chaos Theory is a dynamic systems theory which describes organizational processes which change over time. In this study, the choice of an insurance company is a classic example of a nonlinear system (i.e., a system in which minor events have the potential to set off grave consequences or chain reactions, and major changes may have little or no effect on the system whatsoever). Organizational expectations for acceptable behaviour, and the degree of freedom with which individuals are allowed to work shape the way a company's problems and challenges are handled by its members (Chen and Xinghuo, 2003).

\subsubsection{Complexity Theory}

The origin of complexity theory can be traced to the work of researchers who wanted to discover the hidden order of complex systems within organizations and to find ways to harness these systems for effective management of organizations (Reyes et al., 2013). One objective of complexity theory is to achieve a balance between order (law) and chaos (accident), or between planning and chance (Berwick, 1998; Sullivan, 2004). According to Berwick (1998), this balance is maintained by evolving the strategies of the organization and responding to changing conditions and new customer feedbacks. The central component of the chaos and complexity theories in management is the recognition that change is nonlinear (erratic, unpredictable, unstable) and based on the evolving relationships and complex interactions of the ever-changing components within the system. According to Reyes et al. (2013), understanding complexity and chaos theories allow managers to appreciate the reality of chance in the decision-making process.

\subsection{Contemporary Challenges in the Insurance Industry}

Insurance companies are legal entities with the unlimited number of contents and shapes. As legal entities, they have both physical and legal presence within the country in which they are established (Selimovic et al., 2018). As the Global economy grows, the need for different contents and forms of risk management are required for the continuous protection of assets and lives. The evolving nature of protection needs calls for a permanent demand for maximization of insurance company's risk management, not only as an ordinary but also as a professional challenge. The need for insurance will continue to grow as a result of the economic growth of the countries in which insurance companies exist. However, this growth is not without challenges. The method of price determination involves the use of actuarial calculus and data estimations to determine the optimal sharing ratio with adequate pool for the compensation of the unfortunate few.

Closely associated with the pricing is the challenge of how to formulate the risk portfolio and the investment policy which is capable of yielding excess revenue to cushion the insurance company against fatuitous fluctuation in risk occurrences. As investors, insurance companies contribute investment funds for the financial markets as financial intermediates. A study by Santomero and Babbel (1997) confirmed an insurance industry which is fast changing and which is becoming sophisticated in terms of the level of risk management techniques and approaches, which require continuous improvement. Due to these challenges, the majority of insurance companies are changing their business models to address the emerging insurance market challenges and to maintain their relevance in a competitive business environment.

Insurance companies trade in market risks by amalgamating many individual business risks to create a pool where the unfortunate few get compensation (Hoyt and Liebenberg, 2011). By amalgamating the many individual risks, insurance companies are able to share the few unfortunate losses among the many policyholders and create assurance for continuity of business and quality of life. However a major challenge in the concept of insurance arises from the willingness of individuals with exposure to similar risks (i.e., property damage, health, life etc.) to pool together in order to compensate a pool member who suffers a loss, earn competitive rates of return for longer-term risk protections, generate commensurate rates of returns on the shareholders' wealth (Santomero and Babbel, 1997). It is this onerous responsibility that poses a great challenge especially when an insurance company fails to meet the compensation and investment obligations (Abongo et al., 2018). This occurs in instances where the firm lacks adequate equity to meet their commitments in adverse conditions, or when their losses exceed the expected loss outcomes, a case that often leads to insolvency.

The study reviewed an industry which is experiencing significant changes in the composition of its risk profiles as a result of rapid changes in economics, sociology, politics and the global environment which requires the industry to evolve to sustain future viability. According to Kasturi (2006), even when the outcome of insured risks cannot be fully known, the identification, measurement and management of the risk profiles remain a critical factor to the success of insurance companies operations. Improved technology development is enabling insurance companies to access important client data for greater exploitation of the available market (Ernst, 2018). Today, the use of big data analytics has created a greater understanding of the customer data and insights for strategy formulation on service and product development (KPMG, 2016). By leveraging the big data, insurance companies are able to foster their daily interactions with the market. This daily interaction requires adaptation with the challenging socio-economic business environment and adopting a business model which delivers high investment returns to fund claims payment and generate profit for shareholders (Ernst, 2018).

To be able to meet all these obligations, insurance companies adopt sophisticated techniques of approximating the value of claims and reserving for future exigencies through prudent investment techniques (Faculty and Institute of Actuaries, 1997). In circumstances where they cannot estimate the claims value, or where they are unable to predict natural disasters, they can buy reinsurance covers to cushion them from some of the risks which are beyond their retention (Santomero and Babbel, 1997). Through investment, insurance companies generate a return over and above the average premium collection. These returns are re-invested into the business for stability. However, 
prolonged low-interest rate environment in an economy can be a big problem for insurance companies especially when they fail to generate enough returns from their investments. According to Wilson (1997), risk capital is the amount of economic equity which is adequate to support an insurance company's level of risky business activity. Capital adequacy improves an insurance company's level of safety by assuring solvency standard required for payment of policyholder's losses within an insurance period.

The success of an insurance company is defined by the application of 'the law of large numbers' while striving for the reduction in risk exposure. The law of large numbers states that for a significantly large quantity of independent risks, there is a high probability that the loss expectation is very close to the average (Sain and Selimović, 2015). An insurance company may fail to accumulate an adequate portfolio of a particular risk which meets the requirement for the application of the law of large numbers in the estimation of a loss outcome. In this case, the threat to every insurer is reduced through risk sharing by a large number of independent insurers who undertake joint underwriting of the significant risks designed as cooperation amongst insurers which allows sufficient diversification of risks to avail insurance cover that could otherwise not be offered by only one firm (Sain and Selimović, 2015). This cooperation is one among many product innovations permitting service provision to a segment of uninsured insurance clients.

\subsection{The Kenyan Insurance Industry}

The insurance industry is an important contributor to Kenya's economic development in the same way as banking and investment. In the year 2016, the financial sector contributed $13 \%$ of the Gross Domestic Product (GDP) out of which the insurance industry's contribution was 4\% (IRA, 2016). Beyond this direct influence, the insurance sector plays a significant role in sustaining the financial stability of individuals, families, and organisations by protecting the lives and assets of individuals and organisations. Govind (2009), confirms this important role and the existence of a gap in the protection of lives and assets whenever insurance companies fail to meet the protection needs of the economy. In Kenya, the vision 2030 economic blueprint of July 2012 includes insurance as an important pillar in the Kenyan financial services goals (Insurance Regulatory Authority, 2017). The Kenyan insurance market is made up of 62 companies which transact long-term and short-term insurance businesses and a large number of insurance brokers (AKI, 2018). The industry has a watch-dog, Insurance Regulatory Authority (IRA), whose mission is to effectively and professionally regulate, supervise and develop the industry. Stiff competition among players continues to reduce the insurance companies' ability to pay claims and meet other obligations.

As confirmed by Mutenga (2001), adequate risk financing not only reduce the ratio of assets committed to liabilities but also improve the strength of the insurance company's balance sheet. In the eye of the public, the size of an insurance company is determined by the size of its balance sheet and the level of efficiency in service delivery. Risk financing plays an essential role in determining the cost of an insurance contract per unit of assets committed. According to Dean (2011), financial stability of an insurance company is measured by the level of solvency, capital adequacy and liquidity. An insurance company with low solvency level also finds it hard to cover its liabilities. Such companies will exhibit poor service delivery which includes delayed claims payment. In principle, the biggest challenge of every insurance company is to account for the 'expected' aspects of claims in the pricing of the premium for every policy underwritten. For long-term business, studies have shown a strong relationship between the insurance firm-level risk, and the cost of carry for investments, return on policyholders' surplus and the cost of capital per contract underwritten. Harding (2004), defines cost to income ratio "Cost of carry" as a measure of the total sum of liabilities an insurance company carries on its income.

The cost of carrying is, therefore, a reflection of the money initially spent to acquire the insurance policies. In a situation where an insurance company is adopting a poor pricing policy, the cost of maintaining the systems in the insurance company's books will be significantly higher thus lowering the capacity of the company to generate money through investment. An insurance company that maintains a poor pricing policy for a long time is at risk of either being subjected to technical suspension by the regulator or being wound up altogether. By incorporating solvency requirements in the regulation of insurance companies, the government hopes to improve the performance of insurance companies by ensuring that all insurance companies have adequate solvency requirements for operational efficiency. It is expected that the solvency requirements will reduce price wars and encourage innovation to increase revenue through innovative products (Insurance Regulatory Authority, 2017).

Kenyan insurance market acquired Kshs. 100 billion of Gross Direct Premiums in the year 2017 (Insurance Regulatory Authority, 2018). However, despite this growth, the insurance penetration in the Kenyan economy has remained very low and shows a declining trend, currently at $2.6 \%$, a superficial coverage level which indicates not only the existence of a lot of untapped potentials but also that insurance does not keep pace with the rate of economic growth in Kenya. A study by Wahome (2013), asserts poor public perception of the industry as the problem behind slow growth of insurance in Kenya. Additionally, it has been observed that rate cutting which is lower than the economically viable levels among insurers is common alongside other unconventional competition practices such as the unsustainable employees' incentives so as to grow their business relationships, which have caused insurers to gain very thin premiums which have caused some insurance companies to be unable to meet their obligations, thus lowering the public trust.

\subsection{Jubilee Insurance Company}

The Jubilee Insurance Company is one of the oldest insurance services providers in Kenya with its establishment in 1937 as the first incorporated insurance company, then based in Mombasa, hence has over 80 years of existence. The company grew nationwide as one of the largest insurance companies in Kenya and East African 
region, recently expanding beyond the country to Uganda, Tanzania, Burundi and Mauritius; and has been listed in the Nairobi Securities Exchange, Dar e Salaam Stock Exchange and the Uganda Securities Exchange. The company prides itself with a large clientele of over 450,000 customers. The company is rated highly on leadership, quality and risk management having received an AA- rating in Kenya and Uganda, and an A+ rating in Tanzania.

Jubilee Insurance has experienced great performance and growth in the last decade. The company realised total asset base growth of $9.9 \%$ in 2016 compared to the end of 2015 , dubbed the highest in the Industry. The company also recorded $17.1 \%$ growth in shareholder earnings per share which rose from Ksh. 42.7 to Ksh. 50.0. The company has been reporting an increase in General Insurance underwriting profit, with a combined ratio of $90 \%$ and net positive results in two new life companies in Uganda and Tanzania in 2016. Similar results from the previous years' annual reports with minimal alterations. The company realised these excellent results against the backdrop of an increasingly competitive regional insurance market which has led to softening of insurance premium rates and offered an extremely volatile operating environment which saw major swings in currency values. This study is interested in understanding how Jubilee Insurance can weather the adverse effects of the existing challenges experienced by reviewing the effects of the policies implemented towards solving the challenges.

\subsection{Performance Challenges and Policy Implications in the Kenyan Insurance Industry}

In the organisation context, performance is measured by the outcome of individual employees and the functional units of the organisation (Kasturi, 2006). The idea of performance comes clear whenever a business is considering its perception with the public "Image". The image of a company is determined by the quality of products, service delivery and how it is seen as caring, equal opportunity employer, and environmentally-concerned company (Archakova, 2013). Behind a company's performance consideration are the Individual employee and functional unit's activities that have a significant external influence on the company's consumer behaviour.

It is the responsibility for organisations to develop cultures which have a positive influence on the performance of their companies. This culture exists in an environment where there is proper control of factors affecting the performance of both the individuals and units either formally or informally (Nassazi, 2013). In an organisation, precise controls include the use of structures, standard procedure manuals for operations, customer service charters, and approved budgets. According to Archakova (2013) the majority of organisations use communications, ethics and work culture and different management styles to influence individuals informally. Effective control requires authority levels with defined roles in company performance objectives. Levels of authority are identified by the divisions, subdivisions or units, each with separate responsibilities towards an overall organisational goal.

Within the divisions, subdivisions and units, specific tasks can be assigned through delegation. Whenever a leader decides to delegate, the same leader has to retain the responsibility for the overall performance objective. The specific responsibilities include information and control over the revenues and expenses. In a case study by Peljhan and Tekavćić (2008), it was confirmed that a combination of performance-driven behaviour and regular use of management control systems lead to improved results. Jubilee insurance believes that a careful blend of control systems and strategy have the capability of improving performance as suggested by Peljhan and Tekavćić (2008). One notable philosophy of the company is that failure can be costly if not checked and avoided. Edmonson (2011) links company failures to inadequate control systems which are not backed by strategy especially in an environment which is turbulent and complex. Going by the suggestions of McGrath (2011), the management team at Jubilee are well aware that avoiding failure in a volatile and uncertain business environment is not an option, and that prudent management is required for their company's future survival.

Kenyan Insurance industry has experienced failures that resulted in a number of companies being closed and others restructured to improve quality of service (Ndung'u, 2013), this situation is not unique to Kenya, but similar to what occurs in more affluent countries. In the US and Canadian markets, a total of 102 insurance companies collapsed during the period between 1970 and 2011 (Njeri, 2014). In support of this revelation, Grace and Leverty (2011) pointed at the three waves of insolvencies in Canadian and United States insurance industry. It is interesting that these waves of insolvencies occurred when the insurance industries also experienced poor profitability. A study by Boulding (1969) pointed out that failures are sometimes a natural occurrence that can bring success if valid lessons are identified and learned. In another revelation, Shiv et al. (2005) considered failure are innovation engines for an organisation or an individual. Grace and Leverty (2011), confirms that with proper supervision, the number of such institutions being closed or being subjected technical suspension also decline.

\subsubsection{Intense Competition Among Kenyan Insurance Companies}

Insurance customers pay premiums from the risk pool size and the probability of occurrence of an unexpected outcome. Customer premiums also include elements of the risk of default in line with the cost of carrying methodology (Moss and Kunghehian, 2018). Insurance companies price risk, regulatory costs and the costs of product line subsidisation into their products. This practice compared with the asset and liability management (ALM) in Banks where regulation is on the lighter side for funds transfer pricing (FTP), leaving banks a wide gambit of operation. In this study, the researcher considers the need to align risk-based pricing as a primary driver in the insurance company's resolve to match assets to liabilities. In the event of lower asset value, it becomes more expensive to borrow money from the policyholders. The high cost of carrying ratios result from the poor choice of investments and underwriting practices.

In the long-term, the circumstances within the insurance business may prompt increased default rates among premium payers. The study considers that adopting poor pricing may if not checked lead to lack of confidence of the policyholder, and increase the probability of an insurance company's risk of being subjected to technical suspension 
or even liquidation by the regulator as a result of decreased net asset values (NAV). This situation can trigger a demand for collateral by insurance customers in the form of increased demand for technical capacity to manage the risk portfolio, need to maintain high levels of liquidity or strict investment policy which does not favour diversification. The existence of elements of poor pricing policy among Kenyan Insurers confirms that the insurance industry players have not fully embraced regulation as an essential guide for pricing of insurance products (Abongo et al., 2018). Evidence exists to suggest the existence of a missing link in the relationship between insurance marketing and the principles of good governance. Moss and Kunghehian (2018), indicates that whenever firms attempt to augment, or even override the critical drivers related to internal risk assessment pertaining to client risks, by directly linking product pricing to regulatory costs, the penalties often arise result from the sanctions from the regulator to cover for the overlooked lower prices for insurance products.

\subsubsection{Failure as an Organisational Challenge}

From the University of California, Keith Simonton a psychology researcher and professor considered innovation as the only way to counter the problems of the modern business environment (Shellenbarger, 1999). In one of his studies, he pointed out that successful innovations are a blend of good and bad ideas. According to (Townsend and Wilkinson, 2010), teamwork was seen to improve innovation. He noted that in a situation where there is no teamwork and where employees do not express their ideas and where the culture of trust is not inculcated in the organisation, even the best innovation fails to spur the market (Valacich et al., 1994). This is an indication that lack of trust among teams reduces employee's decision-making capacity and instils fear and eventually leads to failure. According to Shiv et al. (2005), the mindset relating to the perception of failure is closely associated with the fear of making mistakes. Under such circumstances, the majority of employees and managers shy away from taking full responsibility for their decisions, especially where an error is likely to be costly. This fear is partly due to emerging management practices which emphasises on getting it right the first time and every-time ("Total Quality Management").

In the modern operating environment, the global insurance industry is experiencing substantial challenges in the way they are implementing new procedures and processes. On top of the external influences which include the economic pressures and regulatory reforms, there are some other key factors affecting insurers. These factors are pushing insurance firms to adapt and adjust their practices and processes to satisfy the ever-changing client expectations (http://www.incom-business-systems.co.uk). The essential insurer activity, mission and vision, and business environment are ultimately hinged on the need for efficiency. This means that a manager's consciousness of the existence of challenges within a business environment has a significant impact on performance.

Insurance products exist to fill the identified gaps and the need to mitigate risks which affect business. Designing suitable products require identification and clustering of insurable risks according to characteristics which define the relevant products to be created to provide synergetic impacts for individuals, legal entities, local community, and states exposed to the identified risks. This task is highly complex, demanding, and full of challenges, which therefore requires optimal and focused attention to address the changing contemporary operating environment and to call upon insurers to create more and more products, primarily due to the competitiveness among the players in the sector. It is agreed that insurance exists to fill the product and service gap which result from the risks within the business environment. In a situation which is risk-free, the idea of risk management does not make sense.

According to Kasturi (2006), the need for adequate performance controls are the reasons why organisations use divisions and subdivisions to devolve service delivery and create distinctive competencies by bringing services to the people. The challenge with the use of divisions and subdivisions is that whenever co-ordination fails within the central control centre, service delivery at the division or subdivision is also affected. According to Barclay and Smith (1999), the financial structure of an insurance company determines risk-taking behaviour regarding the level of capital available and depends on what each stakeholder perceive to be adequate protection or return on investment. This capital is necessary for the management of the risks which are inherent in the company and which prevent free coordination between the central control unit and the divisions or subdivisions.

Over the last five years, the insurance penetration rate has remained lower than the growth of Gross Domestic Product (GDP), an indication of weaker consumer confidence in insurance (Association of Kenya Insurers, 2018). This is partly due to historical experiences from the failed insurance companies, and also due to the failure of the insurance industry to innovate themselves as essential players in the financial market. But assessing from what is going on in the market, the researcher believes this slow rate of insurance market growth is the result of intense price wars by insurers who fight to increase their sales by charging lower prices which are not determined by the law of large numbers. This observation is consistent with Wahome (2013), where under-pricing for survival took centre stage in an environment where insurance companies fight viciously for the piece of the pie as underwriting profits for the industry stagnates at an average rate of 3\%. There is fear that this trend will reduce the insurance companies' ability to adequately address the recurrent expenditure needs if the market continues to experience weak pricing and increased fraudulent claims.

\section{Methodology}

This study is designed to explore the contemporary challenges, policy interventions and performance of Insurance Companies in Kenya through a case study of Jubilee Insurance Company. The study adopted an exploratory research design. This design allowed the survey to apply qualitative and quantitative techniques in a case study, involving in-depth interviews and document analysis to collect data from one insurance company in Kenya 
and to assess the contemporary challenges, policy interventions and performance. Jubilee Insurance Company was chosen as the case study since the company has the most extensive client network in Kenya and is bound to experience these challenges within the Country. The study was informed by primary qualitative information collected from Jubilee Insurance Company and other secondary data sought from the company. The researcher collected themes by the chairmen of Jubilee Insurance during the ten years of the study and analysed these themes to confirm the results of the quantitative data over the same period. The quantitative and qualitative data was analysed using time series method to inform the study findings. This study emphasises the new approaches of managing companies with the focus on future survival in a business environment which is becoming more turbulent, unpredictable and where business models are never static and where businesses and markets are complex adaptive systems, using complexity theory to increase understanding of how to cope in complex and turbulent environments, this area has not been widely researched in Kenya making it an area of interest especially in a time insurance companies are complying with regulations relating capital adequacy requirements and international reporting standards (i.e., IFS 9 and 17 and Solvency II requirements).

\section{Findings}

This study sought to look at the contemporary challenges facing Jubilee Insurance Company and its linkage to organisation performance. Jubilee Holdings Limited is a limited liability company incorporated and domiciled in Kenya. The company has a primary listing on the Nairobi Securities Exchange and is cross-listed on the Uganda Securities Exchange and Tanzania Stock Exchange. The Company through its subsidiaries and associates (together forming the Group) underwrites Life and non-life insurance risks, such as those associated with death, disability, health, property and liability. The Group also issues a diversified portfolio of investment contracts to provide its customers with asset management solutions for their savings and retirement needs. All these products are offered to both domestic and foreign markets. It has operations in Kenya, Uganda, Tanzania, Burundi and Mauritius and employs over 500 people through its subsidiaries.

The insurance business of the Group is organised into two main divisions, short-term (general) business and long-term (life) business. Long-term business relates to the underwriting of life risks relating to insured persons, the issue of investment contracts and the administration of pension funds. Short-term trade relates to all other categories of insurance business written by the Group, analysed into several sub-classes of business based on the nature of the assumed risks with with a view to diversifying the Group's income base, operational activities have been extended to include fund management, property development and management, power generation and international fibre optic broadband cable connectivity. Within the last decade, Jubilee Insurance posted improvement in their performances despite the challenging operating environment.

\subsection{Performance of Jubilee Insurance}

In the study, Jubilee Insurance performed well during the ten years of the study. The results revealed year on year growth in assets, revenue and equity. Figure 4.1 represents the overall growth equity, income, assets and liabilities over the ten years of the study.

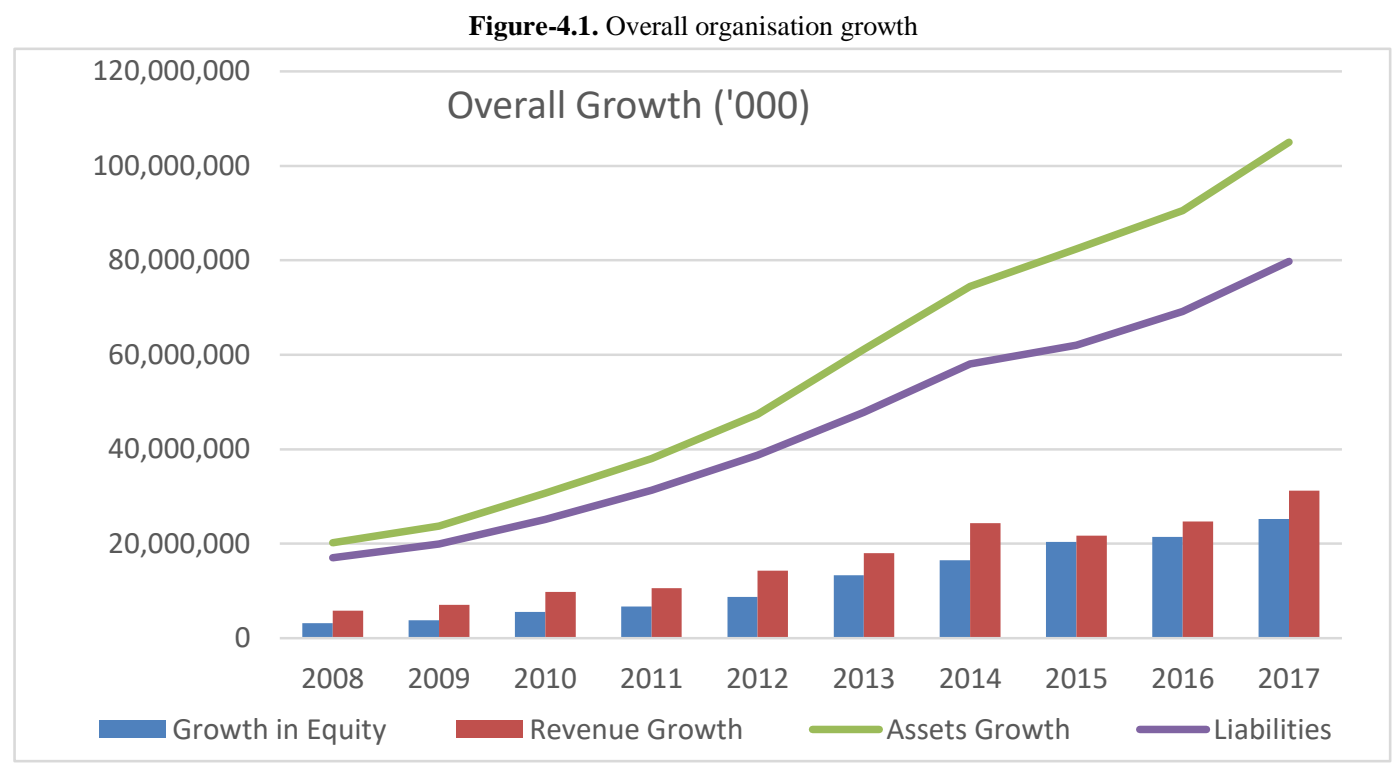

Figure 4.1 The results were obtained from annual financial reports of Jubilee Insurance Company covering 10 years between 2008 and 2017. The outcomes indicate a growing trend exhibited by very high levels of assets growth from a low level of Kshs. 20.2 billion in 2008 to Kshs. 104.9 billion in 2017; a more than five times growth in assets over the last one decade. Though the liabilities were relatively high with increasing trend (a usual expectation of any insurance firm due to insurance contracts), the critical observation was a widening gap between assets and liabilities indicating improvements in the overall state of the company. A similar view was made in regards to revenues where it was observed that the revenues had an increasing trend from a low of Kshs. 5.8 billion in 2008 to Kshs. 31.3 
billion in 2017 (more than 500\% increase within the last decade). The study also observed growth in equity levels where it was observed that equity grew from a low of Kshs. 3.2 billion in 2008 to Kshs. 25.2 billion in 2017 (more than $787 \%$ growth in equity within the last decade). This organisation growth is humongous for the insurance company, with the company breaking the Kenyan boundaries into the East African region entering Uganda, Tanzania and beyond East Africa into Burundi and Mauritius within the 2008 to 2017 period.

Further assessment of the revenues realised by Jubilee Insurance over the study period revealed that total revenues increased significantly from Ksh. 5.8 billion in 2008 rising to 31.3 billion in 2017; though the company reported a trough in 2015 and 2016. Most of the revenues accrued were from insurance premiums which indicated similar growth trends as that for total revenue, while other investment profits were observed to be lower but also had an increasing trend over the study period. Insurance premiums offer the largest source of income for the company with least contribution of 55\% being observed in 2010 and the highest input being recorded in 2008 and 2016 of $71 \%$. On the other hand, other revenue sources which mainly include revenues from non-insurance investments contributed the least amount of $29 \%$ in 2008 and 2016 and highest at $45 \%$ in 2010. These outcomes show that Jubilee Insurance company's revenues are growing year over year at a high rate and that the company mostly rely on revenues from Insurance section of their business which is complemented by their investment in other revenuegenerating ventures as a risk mitigation plan. These outcomes are presented in Figure 4.2.

Figure-4.2. Revenue Growth and Sources

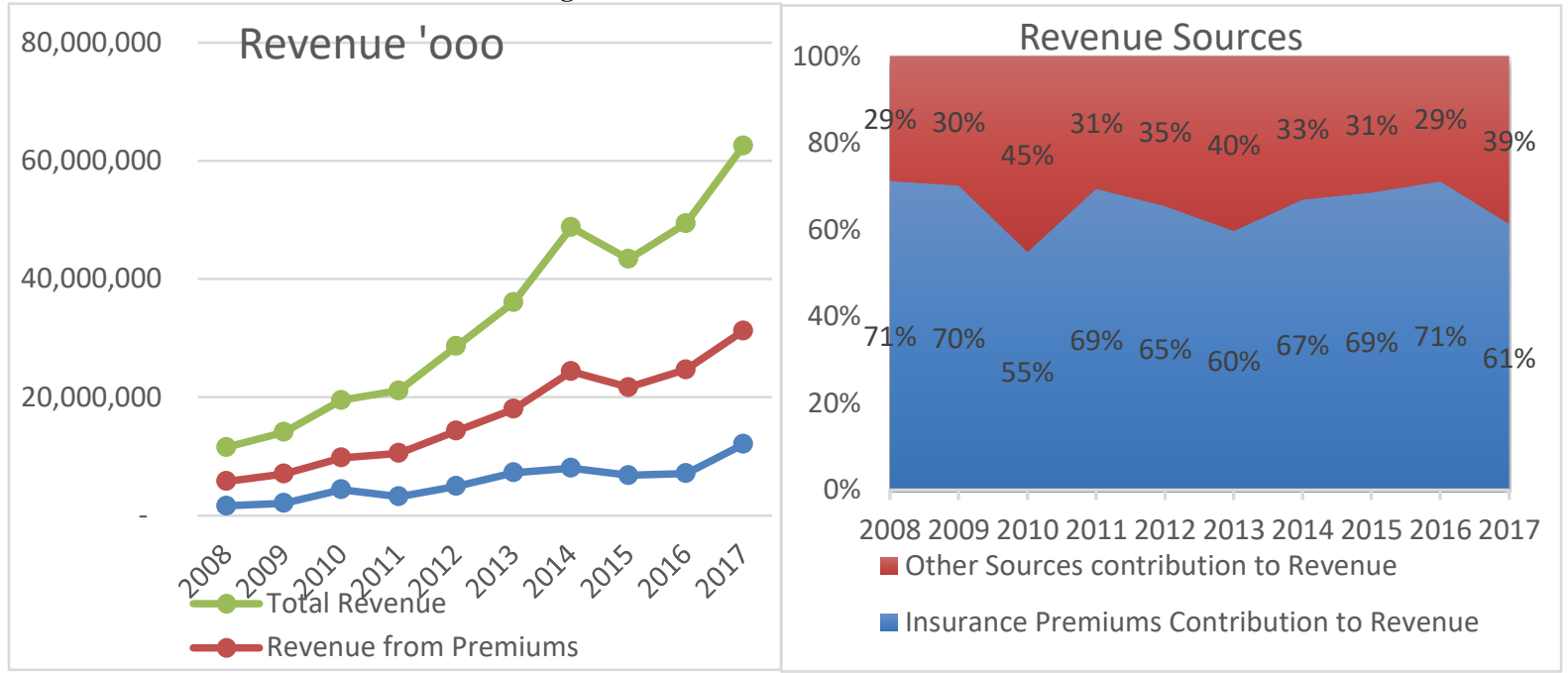

The study looked at the costs side of the organisation where the study found that benefits and claims were the highest costs that Insurance Firms accrued over the study period while expenses and commissions were observed to be lower but with a moderately increasing trend as shown in Table 4.3. The benefits and claims were found to have an increasing trend until 2015 when the claims and benefits significantly declined, only to slightly increase in 2016 with the earlier trend being observed to be re-established in 2017. Earlier, the study found a decline in revenue gains in 2015 and 2016; the same outcomes were replicated with the finding that the reduction was reproduced with a decrease in benefits and claims within the same period, though the expenses and commissions maintained its trends. This hints a linkage between benefits and claims costs and revenues accrued by the company with increased benefits and claims showing an increase in revenues of the company. Assessment of the two cost items as a proportion of total cost revealed that benefits and claims covered at least $63 \%$ and at most $73 \%$ of the expenses while expenses and commissions were at least $27 \%$ and at most $38 \%$ over the study period. These outcomes are presented in Figure 4.3 .

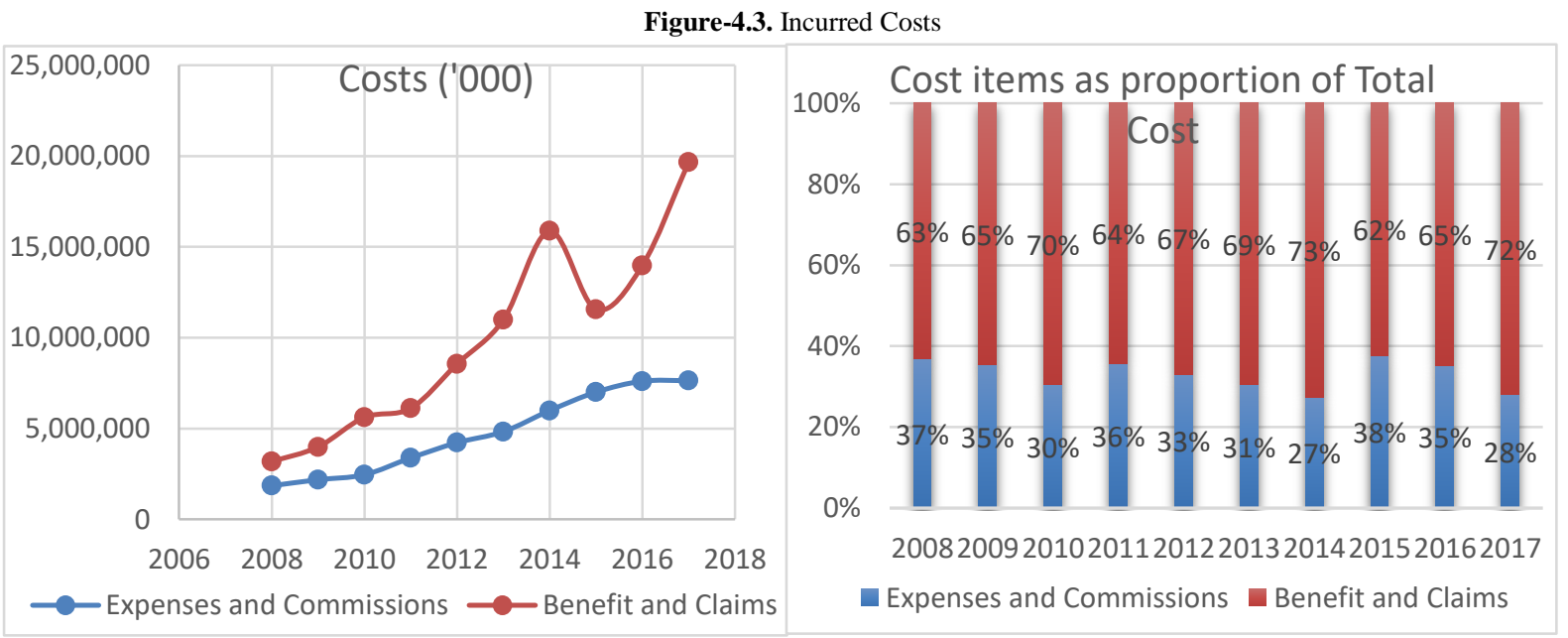


The study observed that from the direct look of the company under review, the direct indicators show a company doing pretty well despite the turbulent operating environment. The study employed various performance ratios to assess the profitability of the company such as return on assets (ROA), return on equity (ROE), and the profit margin ratio, the outcomes of which are presented in Figure 4.4.

Figure-4.4. Jubilee Insurance Profitability

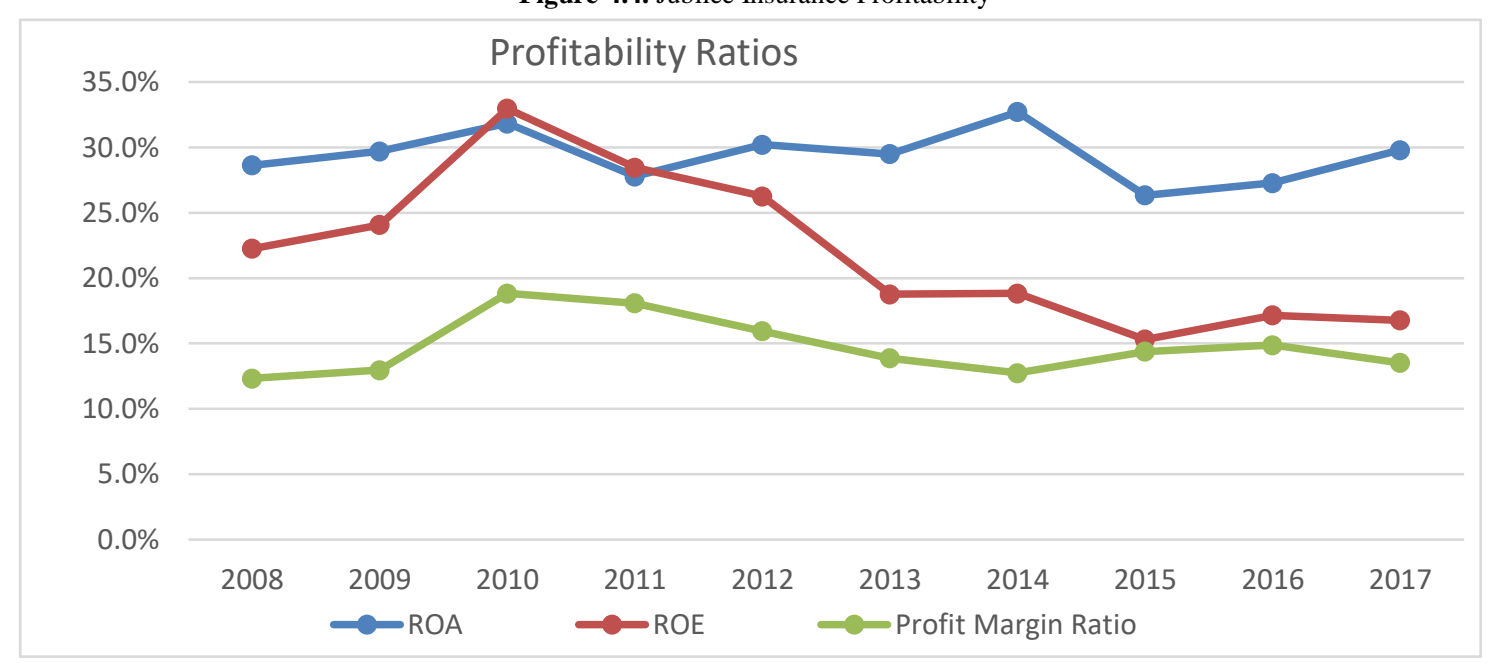

The ROA indicated high profitability levels at Jubilee Insurance at around 30\% with the graph showing a nearly linear trend line with troughs in 2011 and 2015. The ROE, with the highest being 33\% in 2010 and least being $15.3 \%$ in 2015, indicated increasing trend between 2008 and 2010, then a steep decline between 2010 and 2015 , which stabilised thereafter in the years 2006 and 2017. The profit margin ratio indicated a similar trend with a slight increase between 2008 and 2010; a minimal decline between 2010 and 2014, and little increase after that which tapered off in 2017. Despite their variability, none of the ratios declined into the negative side of the curve, an indication that though the profitability levels are not that high, and the company is enjoying positive profits over the years with instances where the benefits have increased year on year.

Figure-4.5. JHL Share Prices

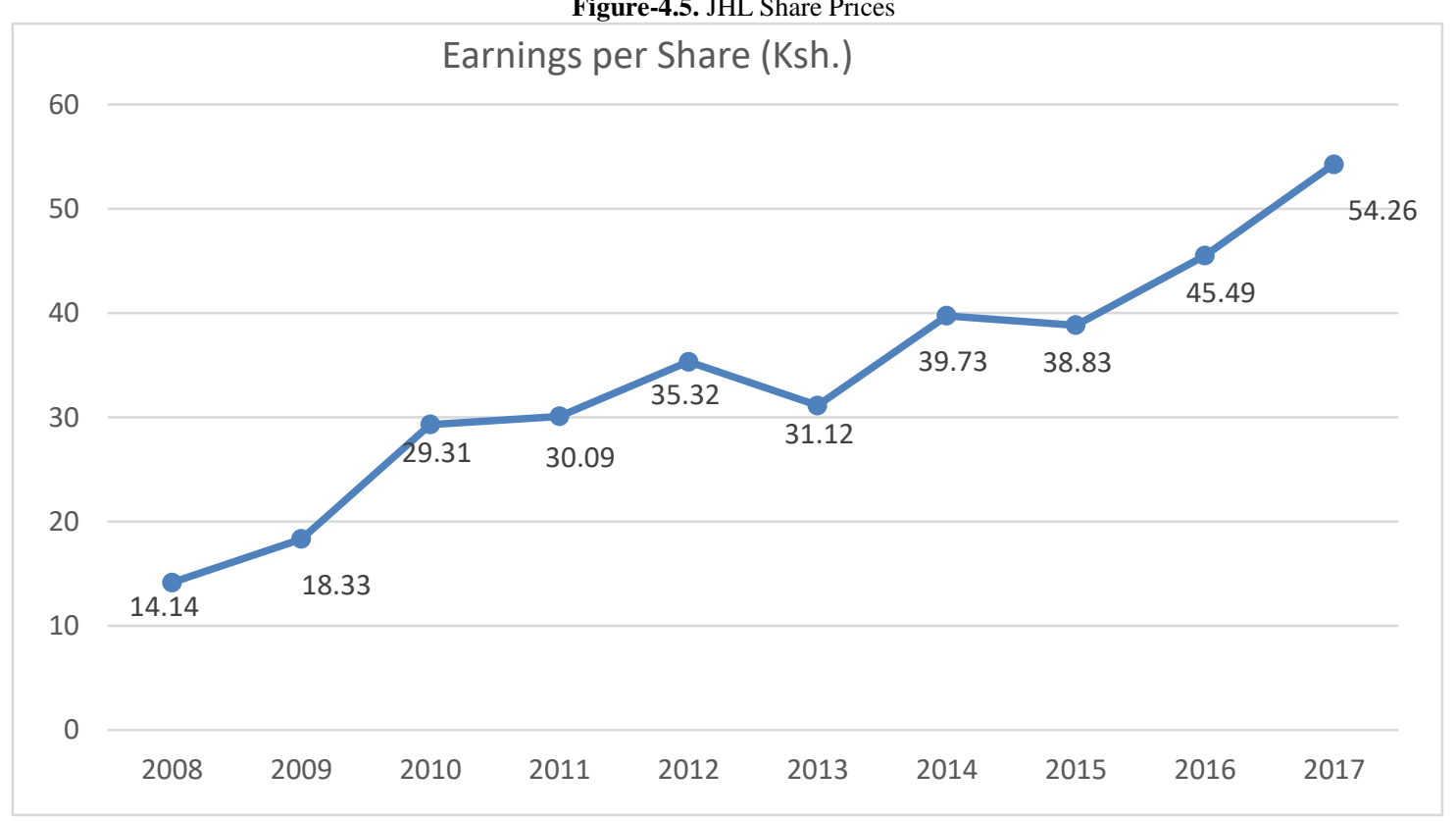

As presented in Figure 4.5, the study found that the share prices of Jubilee Holding Limited (JHL), the trading name for Jubilee Insurance Limited have been increasing over the years from a low of Ksh. 14.14 in 2008 rising over the ten years period to Ksh. 54.26 in 2017. This shows increasing shares value for the company with the shares nearly quadrupling in the study period of 2008 to 2017. The increase in share value has the potential to attract new investors who are assured of a return on their investment.

The study further looked at the company solvency and liquidity. When assessing the company leverage ratio, the study observed a very high but slightly declining trend over the study period, with the highest leverage index being observed in 2008 of 6.3 and the lowest being 4.16 in 2017. The liquidity ratio was found to be varying slightly over the study period with a decline between 2008 and 2011, a slight increase until 2014, a decrease in 2015 and 2016 , and an increase in 2016 and 2017. The lowest liquidity ratio was reported as 0.95 in 2011, while the highest reported over the period was 2.98 in 2017; an indication that despite the variability, the company is well positioned to meet its 
current liability needs without raising external capital. The solvency ratio indicates a very slight increase over the study period was starting at 1.19 in 2008 and ending the period at 1.32 in 2017; an indication of improvement insolvency within the study period. All these indicate that the company is has been enjoying both liquid and solvent positions within the industry, confirming that the company is fully able to meet its short term and long term financial obligations.

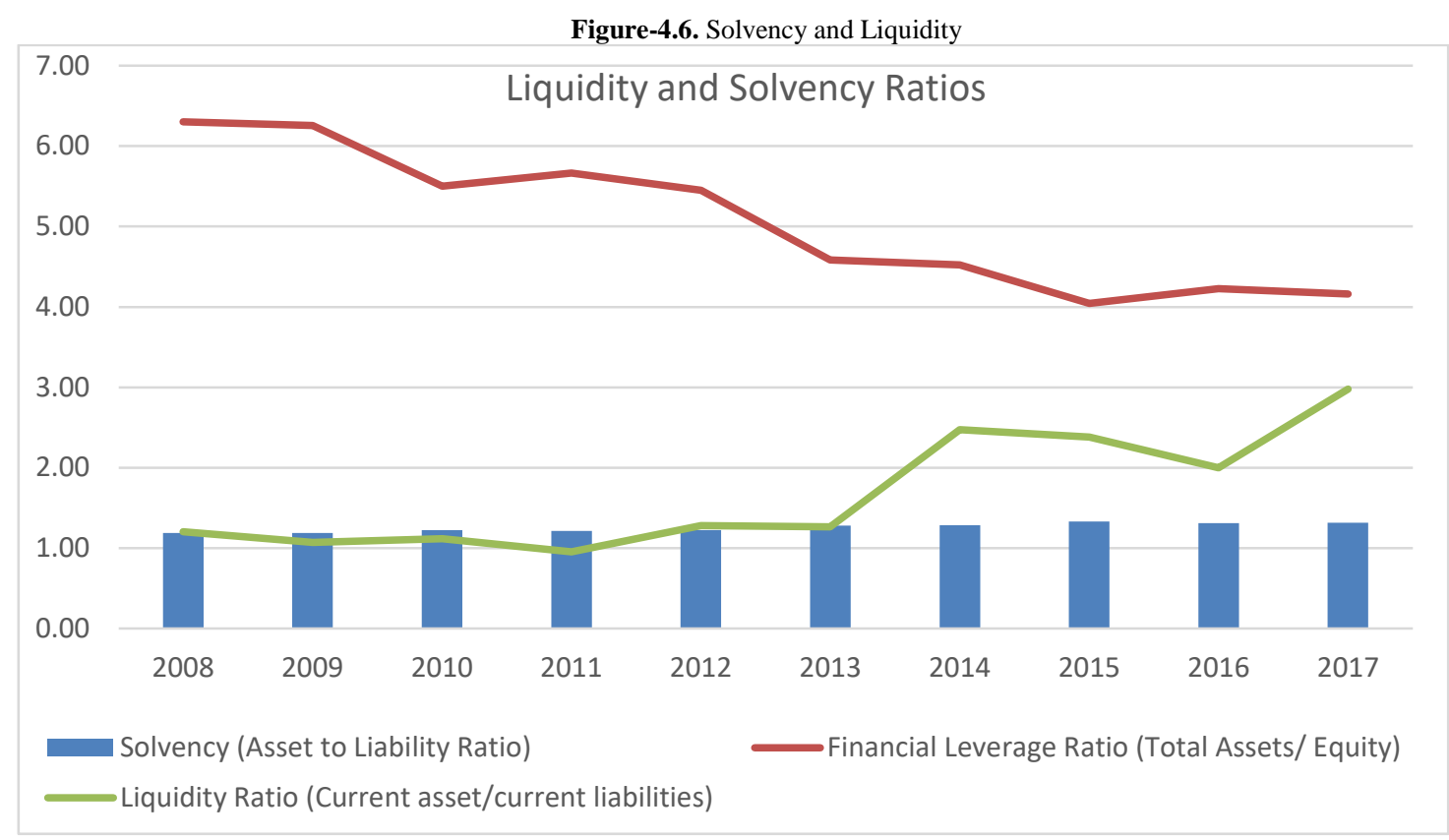

These performance indicators show the current representation of the financial performance status of Jubilee Insurance. From the assessment, the performance of Jubilee Insurance Company during the years from 2008 to 2017 can be described as "very good" with expectations of accelerated growth shortly. The paper finds that Jubilee Insurance has been a very successful company while operating within a highly turbulent environment.

\subsection{Contemporary Challenges and Policy Interventions in Jubilee Insurance}

At each end of year financial report published annually between 2008 and 2017, the board of Jubilee Group acknowledged that Jubilee insurance performance well under 'a very treacherous operating environment'. According to the integrated report \& financial statements of 2017, the chairman, Mr Juma confirmed that the year 2017 was not easy for the company, however, the company through proper leadership and solid internal processes and procedures, the company was able to achieve "...sustainable profitability in an increasingly competitive and corrupt business environment". The regional Chief Executive Officer " Dr Julius Kipng'etich" links this success to the culture of teamwork and innovation. These characteristics have earned the company a competitive edge among the peers and positioned the company as a world-class insurance solutions provider in Kenya.

According to Mr Juma, "The excellent bottom line results were achieved against the backdrop of a difficult year for the insurance industry. The protracted uncertainty linked to the political process in Kenya led to a slowdown in the economy in the second half of the year and delayed new investments in infrastructure and other major projects, and was compounded by unclear Government policy in other parts of the region, weak agriculture output due to drought, and accompanied by tightening private sector credit conditions. A significant drop in the yield curves across the region led to lower returns on fixed income securities and higher long-term insurance contract liabilities computed at a lower discount rate. Appropriate pricing of risk by industry participants continues to be weak, and the drive to gain market share by a number of competitors resulted in severe rate cutting and subsequent significant underwriting losses, " Mr Juma; Jubilee Group Chairman; 2017.

During the release of the integrated report of 2016, the Chairman, Mr Nizar N. Juma still observed as follows:

"We have weathered the tough environment to post the best results in this sector with all business segments and operations posting positive growth. Against this background, I am especially pleased to report that Jubilee increased its General insurance underwriting profit in 2016 with a 90\% combined ratio and our two new life companies in Uganda and Tanzania achieved positive net results, in only their second full year of operation."

This challenging business environment has persisted for a long time, a similar report from Jubilee indicating that even in the year 2012; the insurance business environment was experiencing significant challenges which hindered the uptake of insurance in Kenya.

"The regional insurance market continues to face various challenges including shallow insurance penetration, increased competition due to the arrival of new entrants in our markets and banking legislation challenges which have continued to constrain the development of bancassurance. Despite these challenges, Jubilee has been able to consolidate its market leadership in Kenya, Uganda and Tanzania and also made important gains in market share in Mauritius and Burundi." Mr Juma; Jubilee Group Chairman: 2012. 
Going by the observations of the chairman of Jubilee Holdings Limited, the findings confirm a turbulent global operating environment, which insurance companies must prepare to overcome. On top of the external influences which include the economic pressures and regulatory reforms, there are some other key factors affecting insurers, pushing them to adapt and adjust their practices and processes to satisfy their client expectations. The essential insurer activity, mission and vision, and the business environment is ultimately hinged on the need for efficiency, hence the realisation the challenges may have a considerable impact unless solutions are quickly imposed.

Some of these challenges are:

\section{a. A Changing Consumer in the Insurance Market}

In Kenya, the demand for insurance products is driven by the exponential increase in the household savings, purchasing power, the middle class, and country working population. Under normal circumstances, intense competition is believed to create an impression of vibrant market opportunities which increases the appetite for new investors in the same industry. Other than intense competition, the emergence of the millennial customers, which comprises of the individuals born approximately between 1980 and 2000 into the workforce, a generation constituting half the global workforce by the end of the decade? The insurance sector is facing the need for new products which meet the requirement for a generation which is highly exposed to digital technology and various innovative platforms from an early age making them the "digital natives" the first generation, have begun moving into their peak productivity period and are currently the most influential population segment. They are characterised by a high reliance on technology-based services, transparency, convenience, regular engagement, speed, and personalised experience which echoes their prerequisites on the delivery of and access to products and services. Their inclinations and expectations are challenging to the insurance industry.

The contemporary customers which now include the millennial has undergone significant changes in the recent past. The customers are progressively becoming more demanding and more robust to satisfy, with expectations of the organisations to answer all their enquiries in one interaction, irrespective of the communication channel used such as calling a contact centre, talking to a sales advisor or using digital channels like web chat. A study conducted in Pakistan indicate cases of new 'autonomous customers' who snub automatic brand loyalty, instead of turning to family, friends and other users they interact with online or in social media to inform and uphold each of their purchase decisions (Areeba et al., 2017). This emerging customer breed applies self-service to remain in control, has a low level of loyalty and finds engagement highly difficult. The few times they engage, they have extremely high service delivery expectations. Whenever these customers have an issue, they expect that the call centre agents will efficiently resolve a wide range of issues, from policy enquiries, technical support, and billing and claim management, without unnecessary delays, 'on hold' periods, or any transfer to another department.

This character of the modern customer has led to the emergence of 'super-agent' which majority of the insurers are looking at tools, systems and processes that would help them reinvent their existing call centre agents into the super-agent status. Unfortunately, despite the successes, Jubilee Holdings Limited does not have an active call canter where customers can make enquiries on a 24-hour basis. This is an indication that the company is not prepared to address the emerging needs of the millennial customer. Customers are today becoming increasingly astute, with higher expectations of having access to sophisticated and more personalised communication channels allowing engagement with the insurance provider. This has made customer engagement to be the key priority within the insurance sector with insurers striving to integrate digital strategies revolutionising the customer interaction and connection. The notion of a modern customer requires insurance companies with the ability to distinguish the necessity to enhance their infrastructural and communication platforms, to achieve a lasting foundation for digital transformation. Jubilee Insurance has reacted to this challenge by diversifying their portfolio in the country to meet all the customer needs within the market, the process which allowed the company to tap into the 'middle class' whose needs for insurance products is very high.

\section{b. Stringent Regulations}

The fast-changing business environment is believed to the primary driver for changing regulations around the world. A survey by ACCA and IMA among its membership identified three critical drivers of change in the short, the medium and the long term for a variety of businesses (ACCA, 2013). The study points at the increased need for non-financial information and the continued emergence of integrated reporting models as the critical drivers of change. Evidence suggests that the insurance sector is moving towards greater harmonisation of business standards. By identifying and exploring emerging trends, insurers and business leaders can keep pace with the business challenges of tomorrow. Alignment of business standards is expected to have the most significant impact in the medium term business plans. Greater focus should be to increase skill sets required to manage the changing business requirements.

According to Jubilee Insurance Company, insurance fraud remains a serious concern to industry players, and Jubilee is tightening its controls through dedicated anti-fraud units.

"We are at the forefront in fighting fraud as it is a growing threat to the insurance industry and which increases premium costs for all our policyholders. Jubilee is investing in fraud detection systems and will continue to take vigorous action to protect all stakeholders whenever industry fraud is detected", Mr Juma (2014).

Recent developments have seen the Kenyan government introducing a highly welcomed series of regulatory changes with the objective of enforcing ethical and responsible business practices which protect the insurance consumer. These regulatory changes will inevitably affect those who are unable to comply. Some insurance companies may have to either close or merge with others to evade the fangs of the law. The new insurance law will 
not only affect the insurance companies but are also meant for the insurance brokers and agents; therefore every insurance practitioner needs to understand the effect of regulations on the company. In a bid to introduce tighter controls in the industry, the insurance act has introduced new legislations portions and made new proposed new ones. These regulations have been reviewed twice in the Insurance Regulations 2015 and the Insurance (Amendment) Act 2016, where further measures have been introduced, and other changes are currently being incrementally developed. In this regard, Jubilee Insurance has been highlighting its compliance levels with the various standards applied in the industry.

"Jubilee is well positioned to meet the requirements of increasingly strict solvency regimes across East Africa, which will be positive for both the industry and policyholder protection. While the Risk-Based Capital (RBC) requirements in Kenya were relaxed in 2016 to accommodate weaker companies, the Regulator has indicated a commitment to the development of the risk-based framework to lead to a higher level of stability and consumer protection in the industry. All the Group's insurance subsidiaries across the region are well capitalized and the Kenyan company continues to be fully compliant with the Risk-Based Capital framework with some of the highest Capital Adequacy Ratio's in the industry," Mr Juma: Jubilee Group Chairman; 2017.

The insurance regulator is implementing a standard on customer protection policy which compels insurers to uphold fair treatment of their customers at all stages of the relationship and which requires insurance companies to undertake self-assessment which allows the insurance regulator to assess the fairness of customer treatment in terms of the amount of information and advice offered to customers, products suitability, and how easy it is to make a claim. The external customer treatment has been extended to the internal customer "Employee" who also has access to fair treatment from the employer. A robust dispute resolution platform is now available for policyholders, employees and insurance companies where issues can be resolved. Though the rules are highly beneficial and guided by the intention to enhance the insurance sector's performance, The introduction of new regulations is costly and time-consuming. Due to these regulations, the customers ultimately end up paying higher premiums for riskier products. Additionally, due to the purely prudential costs, there are increased resource needs ensuring compliance with new regulations. The regulations at times contribute to the rise in premiums organizations try to recover and offset the incurred costs.

\section{c. Product Innovation}

Innovation is fundamental in the development of newer products such as cyber insurance which causes the disruption of the supply chain, or developing incremental products such as the amendment to existing policy terms and bundling or unbundling the risk protections. Research by the Institute of International Finance (2016) identified a variety of breakthrough technologies that are spurring fundamental transformations within the insurance industry. According to Areeba et al. (2017), the emergence of cloud computing, the Internet of Things (IoT), advanced analytics, Telematics, Global Positioning System (GPS), mobile phones, digital platforms, drones, blockchain, smart contracts, and artificial intelligence (AI) have opened new ways to measure, control, and price risk, engage with customers, reduce cost, improve efficiency, and expand insurability. The regulatory changes, particularly those related to microinsurance and policy portability, are avenues through which potential innovativeness in the insurance companies can be realized, while some like the product design guidelines might stifle product innovation if not well conceived and implemented. The microinsurance is vital not only through the socio-economic perspectives but also through insurer perspective of innovative sustainable and profitable future growth. The pension sector with its inadequate penetration level of only $10 \%$ of the working population, provide some great innovation avenues.

The use of these new technologies has opened ground for new insurance products, services, and business models which can address the needs of the millennial customers. Even though emerging technology can provide opportunities for Kenyan insurers to modernise and reinvent themselves, it has the challenge of creating a new competitive environment where well -funded and nimble software-based international insurance companies gain entry into the local market with a focus on the unmet consumer demand, bringing down cost, and providing new services (Abongo et al., 2018). The researcher believes that the best strategy for Kenyan insurers is to enhance their market share through product innovation to meet the demands of the contemporary product customisation requirements of the consumer. Technological innovation is a gateway for improved efficiency and can lower the unit costs, offer improved services, increase flexibility, pay higher commissions, and increase sales (Areeba et al., 2017). The most significant performance boost in Jubilee Insurance lies in their innovative products and diversity of asset base within the operating environment. The company chairman indicated that:

"During 2017, Jubilee pursued parallel strategies to develop its franchise, increase insurance penetration and build sustainable profitability in an increasingly competitive and corrupt business environment. In the short-term business segments (General and Medical insurance) the focus was on building sustainable underwriting profitability; initiatives based on improved risk selection and pricing, coupled with the investment in systems and control enhancements, allowed short-term underwriting profits to increase by $83 \%$ to KShs. 1.4 billion in 2017 , despite a small decline in premium levels, as steps to improve the quality of the portfolio became effective. In the Long-Term (Life insurance and Pension business) the focus was on growth and overall premiums and contributions increased by 22\% in 2017 as efforts to extend distribution reach in Uganda and Tanzania and improve productivity in Kenya were executed," Mr Juma: Jubilee Group Chairman; 2017.

"Jubilee's strategy of diversifying its investment and asset base provided an impressive investment income growth of $17 \%$ largely due to the improvement in the interest rates and the securities market", Mr Juma: Jubilee Group Chairman; 2012 
From the Chairman's speech, it is clear that Jubilee is focused on consolidating the legacy systems as they pursue the parallel strategies to increase insurance penetration and build competitive technological innovations focusing on the millennial customer segment. The benefit of innovation is found in the value proposition that is just unique to allow survival in the highly competitive market. The Kenyan insurance regulatory constraints are apparent for every Kenyan insurer. The requirements for Capital Adequacy and the need to comply with the international standards is exerting new pressure on performance and is quickly showing a deficiency of markets maturity as revealed by the constant risk of mis-selling in the insurance industry. As long as these legacy systems are maintained, product innovation is very challenging and almost impossible. From a mice lens, Kenyan insurers sell almost similar products and charge similar prices; hence product innovation is the sole distinguishing factor. Despite this high dependence on change, the sector experiences shallow levels of innovation, with new product innovation being mainly making small incremental alternatives to existing products rather than radically making new innovative products. This is partly because the assigned tariff primarily dictates the wordings of some of the products like coverage, exceptions and terms. The insurance regulator has relaxed insurers restrictions to innovation given that they offer them liberty to vary prices for the same product and add some slight product variations through add-on covers. However, the regulatory atmosphere characterised by stringent rules and regulations for both incremental and new products makes product innovation difficult. Approval for new products undergoes bureaucratic processes which delay quick innovation. The insurance regulator son ground that public interest has to be given priority in any innovation process. Insurance companies must, therefore, prove that adequate market research has been done and that the products do not affect the customer adversely (Insurance Regulatory Authority, 2017).

\section{d. Greater Communication Need}

The millennial customer expects more from their interactions with insurance companies and is difficult to satisfy. Millennial customers demand a one-stop shop for their questions, whether a policy enquiry, billing query or claim management (Areeba et al., 2017). Unfortunately so, Kenyan insurers are still found in the awkward position with regard to dealing with new risks that are emerging in the business environment today. Such challenges include the need for high-level privacy coupled with an insatiable thirst for more information. It is believed that proper reporting of the insurance company's preparedness for this new customer demands and what they are doing to achieve the emerging tasks are critical to not only the insurance services consumers but also to investors enabling them to have informed judgment critical in gauging insurer ability to attract capital.

Call centre agents typically occupy the front line of customer communications, and it's their responsibility to offer critical interactions with customers, with each conversation being regarded as a 'moment of truth'. Agent performance sets the benchmark for the customer experience, shaping perceptions of the business and influencing the likelihood to engage with or remain loyal to a provider, depending on how closely the provider's service delivery matches their expectations. This is important because customer satisfaction will remain the cornerstone of success, even though the customers don't want to be transferred to other departments or put on hold; they want their questions answered, and problems solved fast, all within a single call.

Besides, those insurance providers that focus on a quality service are more likely to be profitable, and customers with a positive experience are twice as likely to refer friends, with word of mouth remaining the primary factor behind 20-50 per cent of all purchasing decisions. This trend of more demanding customers requires a special kind of agent - forcing insurers to review their traditional practices - and has ultimately led to the emergence of the 'super-agent'. Put simply; it's no longer enough for an agent to answer the phone. To deliver the 21 st-century experience, the new breed of super agents must solve problems, give proactive advice, offer recommendations and provide a "wow" factor that builds trust and engagement. With customers using more devices in more ways, there are new options for customer engagement. Digital innovation is having a profound influence on the insurance sector, challenging providers to evolve their communication strategies to remain competitive. The global insurance industry is entering an unprecedented period of change, with most insurance providers expecting digital technology to transform the market within the next five years.

One of the key drivers is the widespread use of mobiles and smart devices and how this has affected customer demands. Smartphones offer instant access to multiple channels such as email, social media, video and web chat, allowing customers to contact their insurance provider regardless of location and time. This could be to register a claim, query their premium or give feedback via social media. In responding to this challenge, insurance providers are beginning to appreciate the opportunities that implementing a digital strategy offers, by providing new tools for increasing the quality of customer interactions and deepening customer relationships. In turn, this is leading to the realisation that implementing a communications strategy can drive operational efficiencies, especially in the contact centre, where a percentage of calls can be routed via other channels, such as email or video and web chat. This also means that call centre agents have full visibility of a customer's profile. For example, agents can see that a customer sent an email about a claim a week ago and can update them on progress.

Jubilee Insurance has invested heavily in digital media with a fully interactive website where all the company products and all other required information is offered to those with access to the internet. The website is highly interactive with chat options provided where the customer can interact in real time with the organization. Additionally, the company has invested in social media with the company having both Facebook and Twitter accounts. Their Facebook account has 31,443 followers while Twitter account has 13,300 followers who are able to access their periodical communications in real time. The company has also invested in call centres that allow interaction with customers and disburse information every now and then. In their 2017 end of year financial report, the company reiterated that: "the Company realizes the need for the continuous professional development of staff 
members...(and), the Board in each year approves a training budget to enable the team regularly up-skill and keep with the times in the dynamic environment". Periodic training allows employees to be better equipped to handle their customers and ability to gain information handling and dispersal skills, hence their win of 'The ICT Award' in 2011.

\section{e. Technological Disruptions}

The last two decades are characterised by the rapid increase in technological penetration within the computing, financial and communication facilities whose impact on the financial sector has been significant. Technical penetration in the industry has enabled information handling and processing which has had several consequences such as an increase in the range, sophistication and complexity of financial products, and gain of economies of scope arising from the production of commercial products. Technology has offered the insurance sector a leeway to reach out to their customers. It allows the customer to benefit from lower product costs and broader access to information. Nonetheless, the insurance products complexity makes it hard for all the customers to be able or fully empowered to make the right choices without being advised.

Until recently, insurance has been a virtual island in a sea of technological change. While new players worked to disrupt banking and wealth management - after entirely transforming music, publishing, travel, taxis and booking insurance seemed to be operating much as it had for decades. That era of relative stability has ended with the increasing deployment of advanced sensor technologies and related services. Insurance is now, like other major industries, grappling with the risks and opportunities of new technologies. A variety of breakthrough technologies have spurred a fundamental transformation of the insurance industry. Cloud computing, the Internet of Things (IoT), advanced analytics, telematics, the global positioning system (GPS), mobile phones, digital platforms, drones, blockchain, smart contracts, and artificial intelligence (AI) are providing new ways to measure, control, and price risk, engage with customers, reduce cost, improve efficiency, and expand insurability. These technologies are also enabling the creation of new insurance products, services, and business models. And while emerging technology provides opportunities for traditional insurers to modernise and reinvent themselves, it also forces them to respond to new sources of competition from increasingly well-funded and nimble software-based companies that are beginning to make inroads in the market by focusing on unmet consumer demand, bringing down cost, and providing new services.

Technology has introduced economies of scale in the sector. An example is the fact that the risk management tools and processes established to be applied in one segment of the financial services industry such as in assessing credit risk can easily be modified for risk management within other sectors such as insurance, therefore attaining economies of scale and scope in generating cross-sectoral products. New insurance players using digital platforms pose a great competitive challenge to their traditional insurance companies as their low-cost technology platforms, and business models permit asymmetric competition in the insurance value chain. The insurers based on digital platforms are faced with lower legacy costs and can acquire higher specialisation levels, higher agility and risk tolerance with $44 \%$ of insurance tech companies being observed to have less than ten employees. These start-ups exploit technology to lower their operational costs and at the same time enhancing client - user experience by improving convenience, simplicity, transparency, customer engagement, personalisation, and timeliness.

IT decision makers are well aware of the mantra 'more with less'. Business leaders demand enhanced alliances, internally within the business and externally with customers, suppliers, and affiliates, in a bid to improve the business processes and customer support, while at the same time accelerating the time to market, agility and create a culture of innovation. These conflicting demands are driving the need to evaluate ways to minimise total cost of ownership while delivering new services and capabilities. Appraising the skills of various technology solutions to provide robust affordability is a critical decision-making factor for providers and essential for overall success. Against this backdrop, cost of ownership needs to be evaluated against all the various delivery methods and infrastructure alternatives that maximise resilience and scalability.

\section{f. On-Demand Marketplace}

Insurance has been an industry with low customer engagement. A survey by Morgan (2014) in conjunction with the Boston Consulting Group, found that consumers interact less with insurers than with any other industry. Many insurers have limited interaction with a significant portion of the end-consumers because a considerable amount of their business is intermediated brokers, for instance, amassed an impressive $\$ 45$ billion in annual compensation from insurers around the world. Furthermore, the slow digitisation of the industry has hindered a high frequency of interaction between insurers and insured. Lack of more customer touch points has meant that insurers have fewer opportunities to gain insight into customer needs and to use ideas to customise products. A desire to become more consumer-centric and augment personalised services is shared throughout the industry.

\section{g. Compensation}

It has been reported as challenging to control the expenses in the insurance industry with most of these expenses being incurred on distribution where the issue of effective cost management is strongly attached to effective delivery. There are numerous compensation-related challenges for insurers affecting the efficiency of their distribution models to deliver on objectives. Specific to tied agents, the compensation framework does not provide for treating a tenured and high performing agent as different from others and allow payment of higher commission rates or support allowances to encourage such agents. Also, there is no mechanism, which provides compensation to an individual agent for any other services rendered by him to the insurer. 
Further, the regulatory compensation structure does not differentiate between a retail agent and an organised distributor such as a corporate agent or a broker. They are paid similar commissions. Besides, the commission rate decreases after ten years of existence of an insurer, which imposes further burdens. Corporate agents also help reduce the distribution expenses of an insurer through the provision of infrastructure, human resources supply and assistance in marketing but are not permitted to be compensated beyond the stipulated commission structure.

Low penetration continues to be a critical hurdle for insurers. To increase the reach, insurers need to tap rural and semi-urban areas. As the cost of setting up operations in rural/semi-urban areas is far lower as compared to those in metros and urban areas, adopting suitable and cost-effective strategies to tap these areas will not only help increase penetration but also efficiently manage distribution.

\section{Conclusions}

The contemporary insurance company faces a highly volatile and complex operating environment due to the changing global business dynamics. Within this environment, the company faces many challenges whose mitigation has required policy direction, with companies unable to cope being observed to end up in insolvency. The study has identified the key challenges within the Kenyan Insurance sector that have arisen due to these changes observed in the contemporary business environment and highlighted their policy implications. Key finding from Jubilee Insurance is that organizations can perform optimally despite operating in a highly volatile environment and facing great challenges.

One key challenge is that of disruptions arising from technological adoption within the insurance sector. The emerging technologies and innovations are transforming the insurance landscape, enabling fresh ideas of measuring, controlling, and pricing risks; customers' engagement, cost reduction, efficiency improvement, and expansion of insurability (Ernst 2015). Though the technology has created significant opportunities for established insurers to modernize, create new insurance products and services, and shake up the business models, it has also led to entry of new innovative start-ups which have significantly changed the way insurance is traditionally assembled, purchased, and experienced, compelling the established insurance firms to strategize ways of innovating and establishing superior digital experiences than the disruptive new entrants who have made notable inroads in the market by focusing on unmet consumer demands, lowering costs, and providing innovative new services.

This introduces the next challenge facing contemporary organisations, which is product innovation. New entrants have made both competition and partnerships to rise significantly in the last two decades. This has fuelled great product innovation and transformation within the industry. At the same time, another challenge of a highly sophisticated and informed customer has arisen who lacks loyalty to any product or company, making the market to be highly volatile. This has led to the creation of policies addressing issues surrounding comprehensive data regulation with insurance regulators and data privacy rules playing a significant role in determining how insurers can use data and influence the level of product customisation available to customers.

Other notable challenges are the stringent regulations, mostly arising as policy direction reacting to the state of the insurance market, a greater need for communication, and an entirely different customer from the insurance customer of the past. These have led to very major changes in the modern insurance market with rising popularity of new terms such as 'super-agents' concept, new compensation frameworks, automated and self-service call centres for customer care, product innovations and new management paradigms. With these and other changes in the insurance market, the sector has evolved significantly in the last two decades, yet the operating structures and principles remains the same, and performance management systems have had minimal changes which are misaligned with the quick change observed in the other market aspects.

This study, therefore, observed gaps where intervention ought to be undertaken in order to align the various change aspects in the sector and their challenges with policy, principles and management changes to be able to respond to the needs within the industry adequately. The study, therefore, concludes that the contemporary insurance organisation has dramatically changed with the changes in the operating environment, changes that have come with significant challenges to the sector where adequate policy interventions are not fully developed. Empirical research on the effect of these contemporary challenges on the performance of the insurance firms would be a desirable intervention shortly to understand the implications the challenges have on the company survival and success in the industry. The case study upgrades the existing theory and the body of literature by proving that a combination of strategy and management control systems has a significant effect on organization performance.

\section{References}

Abongo, B., Senaji, T. and Mitinda, R. (2018). Influence of strategic decisions on the competitive insurance market dynamics in Kenya. The Strategic Journal of Business and Change Management: Available: www.strategicjournals.com

ACCA (2013). Recognising Regional Difference. Annual Report 2013.

AKI (2018). Insurance industry annual report 2017,.

Archakova, A. (2013). Service quality and customer satisfaction. Case study. Company X. Saimaa University of Applied Sciences.

Areeba, T., Mudassir, H. and Talha, H. (2017). The impact of social network marketing on consumer purchase intention in pakistan, Consumer engagement as a mediator. Asian Journal of Business and Accounting, 10(1): 167-200.

Association of British Insurers (2005). Financial risks of climate. June 2005 summar change. 
Barclay, M. J. and Smith, C. W. (1999). The capital structure puzzle. Journal of Applied Corporate Finance, 12(1): 8-20.

Berwick, D. M. (1998). Developing and testing changes in delivery of care. Ann Intern Med, 128(8): $651-56$.

Boulding, K. (1969). Economics as a Moral Science. The American Economic Review, 59(1): 1-12.

Chen, G. and Xinghuo, Y. E. (2003). Chaos control, Theory and applications, Lecture notes in control and information sciences. Springer-Verlag: New York.

Dean, R. (2011). Insurer solvency standards - reducing risk in a risky business. Reserve bank of New Zealand Bulletin, 74(4): Available: https://www.rbnz.govt.nz/research-and-publications/reserve-bankbulletin/2011/rbb2011-74-04-02

Edmonson (2011). Strategies for Learning from Failure. Harvard Business Review, 89(4): 48-55.

Ernst , Y. (2015). Sustaining growth and innovation in the insurance sector. Insurance governance leadership network.

Ernst, Y. (2018). Responding to opportunities and risks in a changing data landscape. Bank governance leadership network.

Faculty and Institute of Actuaries (1997). Actuarial considerations, Claims reserving manual, bulletin. 2(97).

Farazmand, A. (2003). Chaos and transformation theories, A theoretical analysis with implications for organization theory and public management. Public Organization Review, 3(4): 339-72.

Govind, J. (2009). Customer satisfaction in the general insurance industry. A step towards competitiveness. $A$ Journal of Risk \& Insurance, 4(3): 20-25.

Grace, M. F. and Leverty, J. T. (2011). Property-liability insurer reserve error, Motive, Manipulation, Or mistake. Journal of Risk and Insurance, Forthcoming Insurance, 75(3): 567-91.

Harding, M. L., 2004. "Calculating the carrying cost of inventory." In 89th Annual International Supply Management Conference.

Hoyt, R. E. and Liebenberg, A. P. (2011). The value of enterprise risk management. Journal of Risk and Insurance, 78(4): 795-822.

Insurance Regulatory Authority (2017). Insurance industry report for the period january to december 2016. Available: http://www.IRA.co.ke

Insurance Regulatory Authority (2018). Insurance industry report for the period january to december 2017. Available: http://www.IRA.co.ke

IRA (2016). The code of conduct and ethics for insurance regulatory authority.

Kasturi, R. (2006). Performance management in insurance corporation. Journal of Business Administration, 5(1)

KPMG (2016). Audit committee handbook chapter 5 - part 1. 53 / Q2 2016 / Corporate Governance ednAudit Committee News.

McGrath (2011). Lobbying in Ireland: a reform agenda. Journal of Public Affairs, 11(2): 127-34.

Morgan, D. L. (2014). Pragmatism as a paradigm for Social research. Available: https://doi.org/10.1177/1077800413513733

Moss, K. and Kunghehian, N. (2018). Funds-transfer-pricing in banks, What are the main drivers? White paper. Moody's Analytics.

Mutenga, S. (2001). Risk management for property/casualty insurance companies. City University School: London.

Nassazi, A. (2013). Effects of training on employee performance. Evidence from uganda. School of business economics and tourism. Vaasan Ammattikorkeakoulu University of Applied Sciences.

Ndung'u, N., 2013. "Enhancing the quality of financial inclusion in Kenya." In Central Bank of Kenya. Central bank speech 27 November 2014.

Njeri, M. W. (2014). Determinants of insolvency in selected insurance companies in Kenya. University of Nairobi Repository.

Peljhan, D. and Tekavćić, M. (2008). The impact of management control systems - strategy interaction on performance management, A case study. Organizacija, 41(Research papers Number 5): 174-84.

Peters, T. (1987). Thriving on chaos. HarperCollins: New York.

Reyes, A. D., Lerna, A. D. and Goepel, K. (2013). Reresdiscrepancies between parent and adolescent beliefs about daily life topics and performance on an emotion recognition task. J. Abnorm Child Psychol, 41(6): 971-82.

Sain, Z. and Selimović, J. (2015). Challenges in insurance industry. Interdisciplinary Management Research: 5.

Santomero, A. M. and Babbel, D. F. (1997). Financial risk management, An analysis of the process. The Journal of Risk and Insurance, 64(2): 231-70.

Selimović, J., Pijalović, V. and Mioković, T., 2018. "European Union health systemsand responses to the economic crisis." In September 2018, Health Management with Special Attention to Cardiovascular Diseases, Specialeditions Volume CLXXVII, Department of Medical Sciences, Volume 52,Academy of Sciences and Arts of Bosnia and Herzegovina.

Shellenbarger, S. (1999). Three myths that make managers push staff to the edge of burnout. Wall Street journal:

Shiv, B., Carmon, Z. and Ariely, D. (2005). Placebo effects of marketing actions: Consumers may get what they pay for. Journal of Marketing Research, 42(4): 383-93.

Sullivan, T. J. (2004). The viability of using various system theories to describe organisational change. Journal of Educational Administration, 42(4): 43-54.

Swiss, R. (2004). Understanding reinsurance. How reinsurers create value and manage risks. Available: http://www.grahambishop.com 
Townsend, K. and Wilkinson, A. (2010). Managing under pressure: HRM in hospitals. Human Resource Journal, 20(4): 332-38.

Valacich, J. S., Dennis, A. R. and Connolly, T. (1994). Idea generation in computer-based groups: A new ending to an old story. Organization Behavior and Human Decision Processes, 57(3): 448-67.

Wahome, A. M. (2013). The relationship between risk and capital: Evidence from kenya non-life insurance companies. University of Nairobi.

Wilson, T. (1997). Portfolio credit risk. Risk: 111-17 and 56-61. 